\title{
1 Pathotype variation of barley powdery mildew in Western Australia
}

$2 \quad$ M. A. Tucker*, ${ }^{1}$ K. Jayasena, ${ }^{2}$ S. R. Ellwood ${ }^{1}$ and R. P. Oliver $^{1}$

$3 \quad{ }^{1}$ Australian Centre for Necrotrophic Fungal Pathogens, Department of Environment and

4 Agriculture, Curtin University, Bentley, WA 6102, Australia

$5 \quad{ }^{2}$ Department of Agriculture and Food Western Australia, Albany, WA 6330, Australia

6 *Corresponding Author madeline.tucker@curtin.edu.au

7

8 Keywords: Blumeria graminis, powdery mildew, virulence, pathotype

9

10 Running Title: Pathotype variation in Blumeria graminis. 


\section{Abstract}

16 Barley powdery mildew caused by the fungus Blumeria graminis f. sp. hordei (Bgh) has emerged as the most damaging disease of barley in Western Australia (WA). Many of the available cultivars display high levels of disease in the field when the climatic conditions are conducive. As a result, fungicides have become the main method of disease control in the last 10 years. Different types and sources of genetic disease resistance are available but to optimise their deployment it is necessary to evaluate the spectrum of pathotypes present in the pathogen population.

Sixty isolates of Bgh were collected in the 2009 season from 9 locations, single spored and characterised by infection on reference barley lines and cultivars, 18 unique pathotypes were collected. Virulence against many of the $R$-genes in the reference lines was present in at least one pathotype. Isolates were virulent against 16 out of a total of 23 resistance gene combinations. Undefeated resistance genes included the major R-genes Mla-6, Mla-9, Ml-ra and the combinations of Mla-1 plus Mla-A12 and Mla-6 plus Mla-14 and Mla-13 plus Ml$R u 3$ and the recessive resistance gene mlo-5. There was significant pathotype spatial differentiation suggesting limited gene flow between different regions with WA. On the basis of the results we recommend a number of strategies to manage powdery mildew disease levels within WA. 


\section{Introduction}

Powdery mildew, caused by the fungus Blumeria graminis $f . s p$. hordei, results in major yield losses of barley (Hordeum vulgare L.) worldwide if uncontrolled. The disease is especially prevalent in moderate to temperate growing regions where yield losses can reach $40 \%$ (Chaure et al. 2000). Along with cultural practices, the main control measures are the application of effective fungicides and the use of cultivars with genetic resistance. The challenge for both breeders and growers is the capacity of mildew populations to evolve virulent new forms on resistant cultivars together with fungicide resistant pathotypes (Wyand and Brown 2005). Powdery mildew has a number of characteristics that support rapid evolution, such as large numbers of asexual haploid spores, sexual recombination during the growing season, and airborne dispersal over large distances. Consequently finding effective and durable control measures to constrain powdery mildew fungi represents an important challenge in crop protection research.

There are a large number of mapped resistance genes that could provide protection against barley powdery mildew infection (Czembor and Johnston 1999). These include major dominant $R$-genes, operating at a gene-for-gene level (Flor 1971), the major recessive nonrace specific resistance gene mlo (Buschges et al. 1997) and less well characterised minor genes (Yu et al. 2001). The recessive resistance gene mlo has remained undefeated after 50 years of use, but is associated with a yield penalty (Brown 2002). The use of major $R$-genes offers a rapid way to introgress resistance into current cultivars, but such resistance is seldom durable and is subject to a 'boom and bust' cycle (Hovmoller et al. 2000; McDonald and Linde 2002) when the pathogen population evolves via loss of the corresponding avirulence (Avr) gene. Such a strategy requires knowledge of the pathotypes of the pathogen present in the population. The introgression of a single $R$-gene is doomed to failure but introgression of 
60

61

62

63

64

65

66

67

68

69

70

71

72

73

74

two or more $R$-genes, followed by pathotype surveys that detect virulence corresponding to the deployed $R$-genes, is potentially a viable strategy. As each $R$-gene is defeated, it must be replaced so that cultivars continue to carry one or more effective $R$-genes. As a first step in the process, the pathotypes of the population must be determined and monitored.

The objectives of this study were to i) determine the avirulence genes present in the WA Bgh population ii) determine which $R$-genes still provide protection against infection iii) assess the status of the Bgh resistant cultivars Dash and Barque iv) and provide a baseline of the frequencies of avirulence within the WA population for comparison in future surveys.

\section{Materials and Methods}

Collection and Maintenance of Isolates

Isolates were sampled from nine locations throughout the barley growing region of Western Australia; Perth, Medina, Katanning, Broomehill, Mt Barker, Albany, Boxwood Hill, Gairdner and Esperance. In total 60 isolates were collected from August to October 2009. Tissue segments approximately 7cm in length were excised from infected plants and inserted into slopes of water agar amended with 50 mg. $\mathrm{L}^{-1}$ of benzimidazole (Chan and Boyd 1992). Conidia from each sample were shaken onto cv. Baudin grown under mildew free conditions using the tower inoculation method of Brown and Wolfe (1990) and maintained on benzimidazole agar plates in a controlled environment $20 \pm 2^{\circ} \mathrm{C}$ subject to a $12: 12 \mathrm{~h}$ light: dark photoperiod. This process was then repeated with a single colony to obtain monoconidial cultures. Isolates were subcultured onto cv. Baudin at 7-10 day intervals and shaken 24h prior to use to dislodge old conidia and ensure fresh inoculum for infection. 
Inoculation of Pallas differential lines and W.A. cultivars

87

Twenty three Pallas isolines (Kølster et al. 1986) and three current WA cultivars - Baudin,

Barque and Dash were obtained from Department of Agriculture and Food Western Australia

(DAFWA), South Perth, WA. Seedlings were potted in grade 2 vermiculite and grown in a

mildew free controlled temperature environment subject to a $12 \mathrm{~h}$ fluorescent photoperiod at $400 \mathrm{E} \cdot \mathrm{m}^{-2} \mathrm{sec}^{-1 .}$ A single colony of each monoconidial isolate was used to inoculate the primary leaf of 10 day old seedlings. Leaf segments from each line were inoculated simultaneously using the settling tower method described previously and inserted into benzimidazole agar.

Virulence and Pathotype Designation

A five point (0 to 4) infection type (IT) scale was adapted from Czembor (2000) and used to assign a single infection type to each isolate/cultivar interaction 8 days post inoculation. Isolates that produced an infection type 3 or 4 were considered virulent. A selection of 16 differential Pallas lines was used to distinguish and group isolates into pathotypes. A pathotype encompasses isolates with identical pattern of virulence on the differentials. Analysis was conducted using the HaGis : Spread sheet for Automatic Habgood-Gilmor Calculation V.3.1 (Herrmann et al. 1999) to generate descriptive collection site parameters 106 (virulence frequency, number of pathotypes, virulence complexity, and abundance and diversity parameters shown in table 2).

\section{Results}


110

111

112

113

114

115

116

117

118

Pathotype Complexity and Distribution.

In 2009 eighteen unique pathotypes from 60 isolates were identified in WA sampled from nine sites (Figure 1, Table 1), of which fourteen had more than one isolate.

Insert Figure 1 and Table 1

Pathotypes 4 and 18 were the most abundant, encompassing in total eight isolates each and which showed virulence complexities of six and sixteen respectively (Table 2). Three pathotypes were found at more than one collection site whilst all remaining pathotypes were unique to their site of collection. The diversity parameters of the complete collection of isolates surveyed in 2009 are detailed in Table 2. The mean pathotype complexity, defined as the mean of virulence, per pathotype was 6.89. The most diverse sampling site was Mount Barker, from which a total of eight unique pathotypes were identified (Table 2). Virulence complexity of the pathogen collection (mean of the isolate complexity) was 7.98. However pathotype 18 collected from Esperance had a considerably higher virulence complexity of 15 .

Insert Table 2

\section{Isolate Virulence Frequency and Complexity}

The frequencies of virulence of all isolates on 26 barley lines varied from $0 \%$ (no disease on 7 lines) to 100\% (complete susceptibility in lines P17 and P21 and to cv. Baudin). The Rgenes that were present in the resistant lines were Mla-1, Mla-A12, Mla-3, Mla-6, Mla-14, Mla-9, Mla-13, Ml-Ru3 and Ml-ra (Table 3). 
Insert Table 3

There was no visible infection on the Pallas line harbouring mlo-5. The proportions of virulence were low to the resistance gene Mla-23 (0.13) and to the combination of resistance genes Mla-7 and Ml-LG2 (0.13), Mla-10 and Ml-Du2 (0.13), Mla-12 and Ml-Em2 (0.13). The proportion of virulence to Mla-22 (0.87), Ml-p1 (0.87), Mla-t (0.98) and Mla-8 (0.98) were very high. The proportion of isolates virulent to the other $R$-genes ranged from 0.2 to 0.73. Resistance genes were classified as effective ( $0 \%$ of isolates virulent) compromised ( $0 \%>0.50 \%$ of isolates virulent) and defeated $(0.50 \%>1.00 \%$ of isolates virulent $)$.

The virulence complexity of each pathotype was defined by the total virulence of each individual in the group. The lowest virulence complexity (3), with reference to the differentials lines used, was that of pathotype 11 represented by a single isolate. This isolate carried only avr-a7, avr-aNo3 and avr-a22 (Table 4). The highest virulence complexity (16) was found in a total of eight isolates in pathotype 18 avra-7, avra-NO3, avr-LG2, avra-10, avra-Du2, avr-Em2, avra-22, avr-Ru2, avr-k, avr-nn, avrp1, avra-t, avr-g, avr-CP, avr-La, $a v r-h$ and $a v r-G a$ that corresponding to the postulated $R$ gene in Barque (Dreiseitl and Platz 2012).

Insert Table 4

\section{Discussion}

In 2009 the estimated average annual losses to powdery mildew in Western Australia (WA) were \$33M between 2000 and 2008 (Murray and Brennan 2010), but anecdotal evidence suggests losses have been far higher in recent years. In 2011, 1.55 million hectares of barley were sown in WA (ABS 2012) with the majority seeded with cultivars that are highly 
susceptible or susceptible to powdery mildew infection. Baudin, a high yielding malt grade cultivar has been the dominant choice for growers for the past six seasons. This provided the perfect environment for the Bgh to proliferate, reaching epidemic proportions with losses estimated at $\$ 100 \mathrm{M}$ in the 2010 and 2011 cropping seasons. In addition to yield losses, much of the diseased crop was downgraded to feed quality, resulting in a typical loss of $\$ 200 / h a$.

At present there is a lack of high yielding malt grade cultivars with effective genetic resistance and hence fungicide application has been the main method of control. One economical and environmentally sustainable solution is to breed new cultivars with effective $\mathrm{Bgh}$ resistance genes. However, in order for this solution to be effective there is an absolute requirement for thorough knowledge of the virulence and hence pathotypes (isolates with the same patterns of virulence) within the target population. Virulence surveys of Bgh populations have been conducted in many countries around the world (Czembor 2000;

Czembor and Johnston 1999; Dreiseitl 2008; Dreiseitl and Platz 2012; Hovmoller et al. 2000) but as yet the Western Australian Bgh population has not been extensively investigated. The Pallas near-isogenic lines used in this study were created by introgressing $R$-genes into the barley cultivar Pallas and are a set of 23 genetically near-identical lines differing only in their gene(s) for Bgh resistance (Kølster et al. 1986). By screening collections of isolates on the isolines the virulence present can be determined and hence one can ascertain which $R$-genes could be incorporated into future breeding programs for local Bgh control.

A number of cultivars are recommended to growers in the DAFWA 2013 barley variety guide (DAFWA 2012). Baudin is a sought-after malting variety and has remained one of the most widely grown for the past six years. It is very susceptible to powdery mildew infection which many believe has been the major contributing factor to recent epidemics. Trends predict that 
the popularity of Baudin will now begin to decline as the costs of effective disease control outweighs any end point profits.

Buloke is beginning to gain acceptance in international markets as an alternative to Baudin (DAFWA 2012). With moderate resistance to Bgh it was more widely grown in WA in 2011. Buloke is thought to contain two R-genes, Mla-7 and Ml-La (Dreiseitl and Platz 2012). This survey indicates that both of these R-genes are compromised in WA. Recombination of virulent isolates or mutation would result in isolates capable of infection. Thus Buloke may be predicted to suffer from the well-established bust phase of the boom and bust cycle in the next few years.

Barque is a feed variety classed as resistant to powdery mildew. According to Dreiseitl and Platz (2012) this protection is provided by the presence of the $M l-G a$ resistance gene.

Although not included in this survey, this $R$-gene is also found in cultivars such as Capstan (MS), Commander (MR-MS) and Fleet (MR-MS). The disease resistance ratings of these cultivars are given in parenthesis, indicating that at least some isolates in the WA Bgh population have mutated to $a v r-G a$ and as such this resistance gene is also predicted to be compromised.

Dash is suggested to have the genotype Mla-7, Ml-k1 and Ml-La (Dreiseitl and Platz 2012) and is rated as resistant to powdery mildew in Western Australia (DAFWA 2012). However, this study has shown that these resistance genes are compromised, defeated and compromised respectively. This implies there are no isolates tested in this study in Western Australia that have lost the corresponding Avr-genes collectively. Alternatively losing all three of these Avr-genes may impose a fitness penalty (Brown 2002). 
211 Hindmarsh is accredited as a food variety and carries the Mla-8 and Ml-La resistance genes

212 (Dreiseitl and Platz 2012). Ml-a8 provides no protection against Bgh and Ml-La is now

213 compromised. This correlates with the cultivar's moderate susceptibility towards powdery

214 mildew infection (DAFWA 2012). If the $a v r-a 8+a v r-L a$ genotype increases in the WA

215 population Hindmarsh’s susceptibility could increase to match that of Baudin.

216 Yagan has intermediate resistance to powdery mildew. This is governed by the presence of

217 two major resistance genes, Ml-Ch and Ml-ra (Dreiseitl and Platz 2012). This study

218 determined that Ml-ra still provides effective protection against Bgh in Western Australia; the

219 Ml-Ch gene was not tested.

Our studies indicated that isolates carrying virulence to 16 out of the 22 single or combinations of $R$-genes studied herein are present in the WA population. Major R-gene breakdown has been observed in Europe but the extent in this study was surprising given WA's isolation (Brown 1994). Therefore we can predict that Buloke (and other varieties) will not provide long term resistance to powdery mildew. Therefore any strategy based on major R-genes must incorporate two or more of the following single R-genes Mla-3, Mla-9, Ml-ra and the combinations of Mla-1 with Mla-A12, Mla-6 with Mla-14 or Mla-13 with MlRu3. Future surveys should be carried out to detect mutations to virulence. By testing the Pallas lines P01, P02, P03, P8b, P11 and P14 against a range of isolates, changes in virulence in the local population can be detected.

Experience from Europe suggests the best ways of achieving durable resistance is to use either mlo (Freialdenhoven et al. 1996) or combinations of minor genes. The recessive resistance gene mlo has remained effective for more than 50 years and is the mainstay of 
mildew control in European winter barley plantings. The yield penalties associated with mlo lines are significant (4.2\%, Kjaer et al. 1990) but need to be weighed against some productivity losses and the costs of fungicides. We therefore recommend that serious consideration be given to the utilisation of mlo in WA barley cultivars. One solution to reduce the pleiotropic effects of mlo may be the incorporation of durable minor resistance genes effective against different isolates (Yu et al. 2001). These genes only allow low levels of mildew development and are common in plants, and while few have been isolated, many have been described in barley (Aghnoum and Niks 2011; Jones and Davies 1985).

We discovered significant spatial differentiation for the Bgh population - the highest diversity was at Mount Barker whilst the Perth population was a distinct subgrouping. Bgh is a highly mobile pathogen (Wyand and Brown 2003) and so it was surprising to see such differentiation, which may reflect local cultivar selection pressures. This finding indicates the necessity to carry out field trials in several locations in order to accurately assess the cultivar resistance levels. Possibly the most promising result from this survey is the identification of resistance genes which still provide effective control of Bgh. The introduction of these and exotic genes into future barley breeding programs, along with an integrated fungicide regime, may allow the impact of Bgh to be ameliorated in WA.

\section{Acknowledgements}

This work was supported by funding from the Grains Research and Development Corporation GRS10035. 
258

259

260

261

262

263

264

265

266

267

268

269

270

271

272

273

274

275

276

277

278

279

280

281

282

283

284

285

286

287

288

289

290

291

292

293

294

295

296

297

298

\section{References}

ABS (2012) Australian Bureau of Statistics. In 'Principal Agricultural Commodities, Australia, 20102011. ' http://www.abs.gov.au/ausstats/abs@nsf/mf/7121.0)

Aghnoum R, Niks RE (2011) Transgressive segregation for very low and high levels of basal resistance to powdery mildew in barley. Journal of Plant Physiology 168(1), 45-50.

Brown JKM (1994) Chance and selection in the evolution of barley mildew. Trends in Microbiology 2(12), 470-475.

Brown JKM (2002) Yield penalties of disease resistance in crops. Current Opinions in Plant Biology 5, $1-6$.

Brown JKM, Wolfe MS (1990) Structure and evolution of a population of Erysiphe graminis f.sp.

hordei. Plant Pathology 39(3), 376-390.

Buschges R, Hollricher K, Panstruga R, Simons G, Wolter M, Frijters A, van Daelen R, van der Lee T, et al. (1997) The barley Mlo gene: a novel control element of plant pathogen resistance. Cell 88, 695705.

Chan KC, Boyd WJR (1992) Pathogenic variation of powdery mildew of barley in Western Australia. Australian Journal of Agricultural Research 43, 79-85.

Chaure P, Gurr SJ, Spanu P (2000) Stable transformation of Erysiphe graminis an obligate biotrophic pathogen of barley. Nat Biotech 18(2), 205-207.

Czembor JH (2000) Resistance to powdery mildew populations of barley landraces from Morocco. Australasian Plant Pathology 29, 137-148.

Czembor JH, Johnston MR (1999) Resistance to powdery mildew in selections from Tunisian landraces of barley. Plant Breeding 118(6), 503-509.

DAFWA (2012) Barley variety guide for WA 2013. Department of Agriculture and Food, Government of Western Australia, No. 3836, Perth.

Dreiseitl A (2008) Virulence frequency to powdery mildew resistances in winter barley cultivars.

Czech Journal of Genetics and Plant Breeding 44(4), 160-166.

Dreiseitl A, Platz G (2012) Powdery mildew resistance genes in barley varieties grown in Australia. Crop and Pasture Science, - . 
Flor HH (1971) Current status of the gene-for-gene concept. Annual Review of Phytopathology 9 , 275-296.

Freialdenhoven A, Peterhansel C, Kurth J, Kreuzaler F, Schulze-Lefert P (1996) Identification of genes required for the function of non-race-specific mlo resistance to powdery mildew in barley. The Plant Cell 8(1), 5-14.

Herrmann A, Löwer CF, Schachtel GA (1999) A new tool for entry and analysis of virulence data for plant pathogens. Plant Pathology 48(2), 154-158.

Hovmoller MS, Caffier V, Jalli M, Anderson O, Bessenhofer G, Czembor JH, Dreiseitl A, Felsenstein F, et al. (2000) The European barley powdery mildew virulence survey and disease nursery 1993-1999. Agronomie 20, 729-743.

Jones IT, Davies IJER (1985) Partial resistance to Erysiphe graminis hordei in old European barley varieties. Euphytica 34(2), 499-507.

Kjaer B, Jensen HP, Jensen J, Jorgensen JH (1990) Associations between three $\mathrm{ml}$-o powdery mildew resistance genes and agronomic traits in barley. Euphytica 46, 185-193.

Kølster P, Munk L, Stølen O, Løhde J (1986) Near-isogenic barley lines with genes for resistance to powdery mildew. Crop Science 26(5), 903-907.

McDonald BA, Linde C (2002) Pathogen population genetics, evolutionary potential and durable resistance. Annual Review of Phytopathology 40, 349-379.

Murray GM, Brennan JP (2010) Estimating disease losses to the Australian barley industry. Australasian Plant Pathology 39, 85-96.

Wyand RA, Brown JKM (2003) Genetic and forma specialis diversity in Blumeria graminis of cereals and its implications for host-pathogen co-evolution. Molecular Plant Pathology 4(3), 187-198.

Wyand RA, Brown JKM (2005) Sequence variation in the CYP51 gene of Blumeria graminis associated with resistance to sterol demethylase inhibiting fungicides. Fungal Genetics and Biology 42, 726-735.

Yu DZ, Yang XJ, Yang LJ, Jeger MJ, Brown JKM (2001) Assessment of partial resistance to powdery mildew in Chinese wheat varieties. Plant Breeding 120, 279-284. 


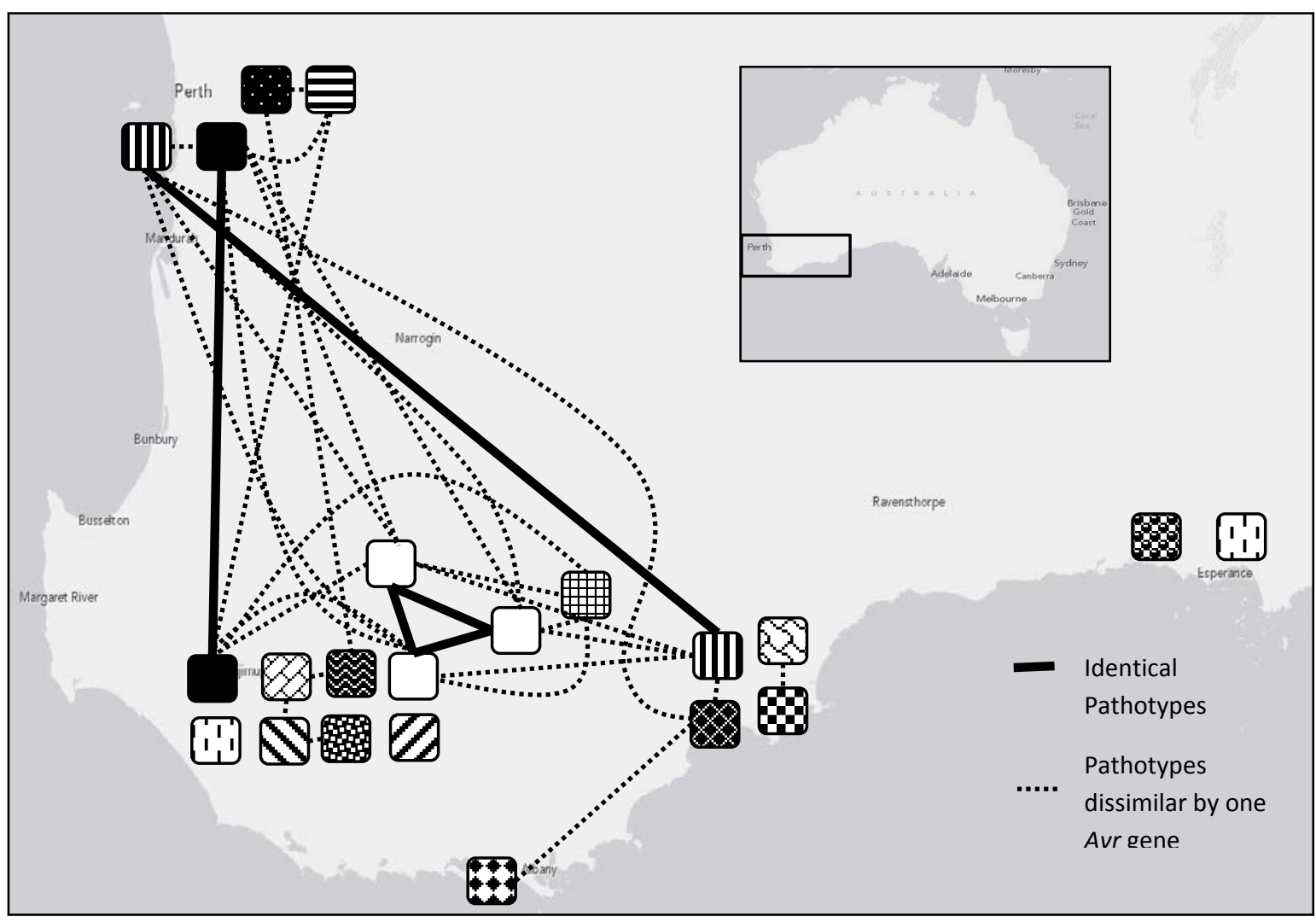

Fig 1 Pathotype map of Blumeria graminis f. sp. hordei in Western Australia. Nine sample sites from west to east are Medina, Mount Barker, South Perth, Katanning, Albany, Broome Hill, Boxwood Hill,

342 Gairdner and Esperance. Individual pathotypes are distinguished by patterned boxes. Identical

343 pathotypes are linked with a solid line. Pathotypes dissimilar by a single Avr gene are linked by dotted lines 
Table 1. Diversity parameters of the Blumeria graminis f. sp. hordei collection from Western Australia

in 2009. Mean isolate complexity is defined as the mean of avirulence genes present in all isolates.

Mean pathotype complexity is defined as the mean of avirulence in each pathotype.

\begin{tabular}{lc}
\hline Parameter & \\
\hline No. of isolates & 60 \\
No. of pathotypes & 18 \\
No. of pathotypes with frequency > 1 & 14 \\
Mean isolate complexity & 7.98 \\
Mean pathotype complexity & 6.89 \\
Diversity - Simple & 0.30 \\
Richness - Gleason & 4.15 \\
Diversity - Shannon & 2.69 \\
Diversity - Simpson & 0.94 \\
\hline
\end{tabular}

350

351 
Pathotype variation in Blumeria graminis

352 Table 2. Complexity of the nine sample sites of Blumeria graminis f. sp. hordei in Western Australia

353 in 2009. Virulence complexity is defined as the mean of the avirulence genes of isolates collected

354 from each location.

\begin{tabular}{lccc}
\hline \multicolumn{1}{c}{ Location } & No. Pathotypes & Pathotypes & $\begin{array}{c}\text { Average isolate } \\
\text { virulence complexity }\end{array}$ \\
\hline Albany & 1 & 1 & 3.0 \\
Gairdner & 4 & $2,3,11,12$ & 4.0 \\
Boxwood Hill & 1 & 5 & 7.0 \\
Broomehill & 1 & 4 & 6.0 \\
Mount Barker & 9 & $4,6,9,10,13,14,15,17$ & 7.7 \\
Katanning & 1 & 4 & 5.0 \\
Esperance & 2 & 16,18 & 15.0 \\
South Perth & 2 & 7,8 & 6.4 \\
Medina & 2 & 3,6 & 5.5 \\
\hline
\end{tabular}

355

356 
357 Table 3. Differential Pallas lines, their genes for resistance to Blumeria graminis f. sp. hordei and

358 proportion of corresponding virulent isolates among Western Australian isolates collected in 2009.

359 An isolate was considered virulent with an IT of 3 or 4 . Lines/resistance genes were classed as

360 effective ( $0.00 \%$ isolates virulent) compromised $(0.00 \%>0.50 \%$ isolates virulent $)$ and defeated

$361(0.50 \%>1.00 \%$ isolates virulent $)$.

\begin{tabular}{|c|c|c|c|}
\hline $\begin{array}{l}\text { Line/ } \\
\text { Cultivar }\end{array}$ & $\begin{array}{l}\text { Resistance } \\
\text { gene/s }\end{array}$ & $\begin{array}{c}\text { Proportion } \\
\text { of isolates } \\
\text { virulent }\end{array}$ & \multirow{8}{*}{ 总 } \\
\hline P01 & Mla-1 Mla-A12 & 0.00 & \\
\hline P02 & Mla-3 & 0.00 & \\
\hline P03 & Mla-6, Mla-14 & 0.00 & \\
\hline P8b & Mla-9 & 0.00 & \\
\hline P11 & $\begin{array}{l}\text { Mla-13, Ml- } \\
\text { Ru3 }\end{array}$ & 0.00 & \\
\hline P14 & MI-ra & 0.00 & \\
\hline P22 & $m l-o 5$ & 0.00 & \\
\hline P06 & Mla-7, MI-LG2 & 0.13 & \multirow{8}{*}{$\begin{array}{l}0 \\
0 \\
0 \\
0 \\
0\end{array}$} \\
\hline P09 & $\begin{array}{l}\text { Mla-10, MI- } \\
\text { Du2 }\end{array}$ & 0.13 & \\
\hline P10 & $\begin{array}{l}\text { Mla-12, Ml- } \\
\text { Em2 }\end{array}$ & 0.13 & \\
\hline P13 & Mla-23 & 0.13 & \\
\hline P24 & $M I-h$ & 0.20 & \\
\hline P4a & Mla-7, Ml-k, +? & 0.25 & \\
\hline P4b & $\begin{array}{l}\text { Mla-7, Mla- } \\
\text { No3 }\end{array}$ & 0.38 & \\
\hline P23 & $M I-L a$ & 0.38 & \\
\hline P15 & MI-Ru2 & 0.65 & \multirow{10}{*}{ 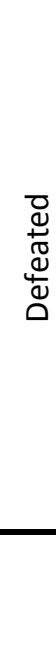 } \\
\hline P18 & MI-nn & 0.73 & \\
\hline P12 & Mla-22 & 0.87 & \\
\hline P19 & $M I-p 1$ & 0.87 & \\
\hline P20 & Mla-t & 0.98 & \\
\hline Pallas & MI-8 & 0.98 & \\
\hline P17 & $M I-k$ & 1.00 & \\
\hline P21 & $M I-g, M l-C P$ & 1.00 & \\
\hline Baudin & $M / a-8^{1}$ & 1.00 & \\
\hline Barque & $M I-G a^{1}$ & 0.54 & \\
\hline
\end{tabular}


Pathotype variation in Blumeria graminis

$362 \quad$\begin{tabular}{ccc} 
Dash & Mla-7, MI-k1, & 0.00 \\
\cline { 2 - 2 } & ${ }^{1}$ Postulated by Dreiseitl and Platz 2012
\end{tabular} 
Table 4. Virulence spectra of 18 pathotypes of Western Australian Blumeria graminis f. sp. hordei isolates. The number of isolates in each pathotype are indicated in parenthesis.

Virulence (+) of the pathotypes to resistance genes and cultivar Barque.

\begin{tabular}{|c|c|c|c|c|c|c|c|c|c|c|c|c|c|c|c|c|}
\hline Pathotype & $\begin{array}{l}a . \\
+ \\
\hat{j} \\
\frac{1}{z}\end{array}$ & $\begin{array}{l}\frac{1}{\Sigma} \\
\hat{z} \\
\frac{1}{z} \\
\frac{\Sigma}{z} \\
z\end{array}$ & 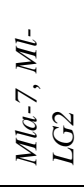 & 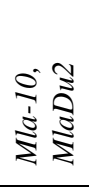 & $\frac{\text { है }}{\text { I1 }}$ & 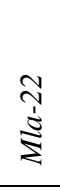 & $\begin{array}{l}\underset{N}{v} \\
\stackrel{i}{z}\end{array}$ & 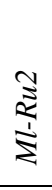 & $\frac{\widetilde{r}}{\dot{z}}$ & $\underset{⿱ 亠}{\mathbb{Z}}$ & $\frac{\vec{i}}{i}$ & $\frac{\tilde{J}}{\Sigma}$ & $\begin{array}{l}\dot{1} \\
0 \\
\dot{1} \\
\dot{z} 0\end{array}$ & $\frac{0}{\mathbb{1}}$ & $\frac{\mathfrak{I}}{\Sigma}$ & 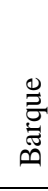 \\
\hline 1 (1) & & & & & & & & & & + & & + & + & & & \\
\hline $2(2)$ & & & & & & & & & + & + & & + & + & & & \\
\hline $3(6)$ & & & & & & & & & + & + & + & + & + & & & \\
\hline $4(8)$ & & & & & & + & & & + & + & + & + & + & & & \\
\hline $5(3)$ & & & & & & + & & & + & + & + & + & + & & & + \\
\hline $6(2)$ & & & & & & + & & & + & + & + & + & + & + & & \\
\hline 7 (5) & & & & & & + & & + & + & & + & + & + & & & \\
\hline $8(4)$ & & & & & & + & & & + & & + & + & + & + & & + \\
\hline $9(2)$ & & & & & & + & & + & + & + & + & + & + & & & \\
\hline $10(4)$ & & & & & & + & & + & + & + & + & + & + & + & & + \\
\hline $11(1)$ & & + & & & & + & & & & & & & & & & \\
\hline $12(1)$ & & + & & & & + & & & & & & & & & & + \\
\hline $13(3)$ & & + & & & & + & & + & + & & & + & & & & \\
\hline $14(2)$ & & + & & & & + & & + & + & & & + & + & + & & \\
\hline $15(1)$ & & + & & & & + & & + & + & & & + & + & + & & + \\
\hline $16(4)$ & + & + & & & & + & & + & + & + & + & + & + & + & & + \\
\hline 17 (3) & + & + & & & & + & & + & + & + & + & + & + & & + & \\
\hline $18(8)$ & + & + & + & + & + & + & + & + & + & + & + & + & + & + & + & + \\
\hline
\end{tabular}

